\title{
THE
}

\section{Implementing a Multi-Component School-based Obesity Prevention Intervention: A Qualitative Study}

\author{
Mary L. Greaney \\ University of Rhode Island, mgreaney@uri.edu \\ Cary K. Hardwick \\ Jennifer L. Spadano-Gasbarro \\ Solomon Mezgebu \\ Christine M. Horan
}

Follow this and additional works at: https://digitalcommons.uri.edu/kinesiology_facpubs

\section{The University of Rhode Island Faculty have made this article openly available.} Please let us know how Open Access to this research benefits you.

This is a pre-publication author manuscript of the final, published article.

Terms of Use

This article is made available under the terms and conditions applicable towards Open Access Policy Articles, as set forth in our Terms of Use.

\section{Citation/Publisher Attribution}

Greaney, M. L., Hardwick, C. K., Spadano-Gasbarro, J. L., Mezgebu, S., Horan, C. M., Schlotterbeck,... Peterson, K. E. (2014). Implementing a multi-component school-based obesity prevention intervention: A qualitative study. Journalof Nutrition Education and Behavior, 46(6), 576-582. http://dx.doi.org/10.1016/ j.jneb.2014.04.293

Available at: http://dx.doi.org/10.1016/j.jneb.2014.04.293 


\section{Authors}

Mary L. Greaney, Cary K. Hardwick, Jennifer L. Spadano-Gasbarro, Solomon Mezgebu, Christine M. Horan, Sara Schlotterbeck, S. Bryn Austin, and Karen E. Peterson 


\section{Implementing a Multi-Component School-based Obesity Prevention Intervention: A Qualitative Study}

Mary L. Greaney, Cary K. Hardwick, Jennifer L. Spadano-Gasbarro, Solomon Mezgebu, Christine M. Horan, Sara Schlotterbeck, S. Bryn Austin, and Karen E. Peterson

Mary L. Greaney, $\mathrm{PhD}$ (Corresponding Author)

Assistant Professor

University of Rhode Island

25 West Independence Way

Kingston, RI

Email: mgreaney@mail.uri.edu

Telephone: 401-874-7499

Cary K. Hardwick, MA, MS, MS

Nurse Practitioner

Holyoke Health Center

230 Maple St.

Holyoke, MA 01040

Email: cary.hardwick@hhcinc.org

Jennifer L. Spadano-Gasbarro, $\mathrm{PhD}$

Research Associate

Harvard School of Public Health

665 Huntington Avenue

Boston, MA 02115

Email: jlsg1023@hotmail.com

Solomon Mezgebu, MS

Senior Epidemiologist

Massachusetts Department of Public Health

250 Washington Street, 4th Floor

Boston, MA 02108

Email: solomon.mezgebu@gmail.com

Christine M. Horan, MPH

Project Manager

Harvard Pilgrim Health Care Institute

133 Brookline, Avenue, $6^{\text {th }}$ Floor

Boston, MA 02215

Email: chrissy_horan@harvardpilgrim.org 
Sara Schlotterbeck, BA

Alpert Medical School

Brown University

Email: sara.schlotterbeck@gmail.com

S. Bryn Austin, ScD

Division of Adolescent and Young Adult Medicine

Children's Hospital Boston

300 Longwood Ave.

Boston, MA 02115

Email: bryn.austin@childrens.harvard.edu

Karen E. Peterson, ScD

Professor and Director, Human Nutrition Program

University of Michigan School of Public Health

1415 Washington Heights

Ann Arbor, MI 48109-2029

Email: karenep@umich.edu

\section{Research Brief}

Abstract $=150$ words

Manuscript plus references $=2,298$ words

Running head: Implementing a Multi-Component Intervention

\section{Acknowledgements}

The Massachusetts Department of Public Health under the auspices of the International Nutrition Foundation, Inc., Boston, MA funded this study. K.E. Peterson was a co-author of the Planet Health curriculum, but she does not receive royalties. S.B. Austin is supported by the Leadership Education in Adolescent Health Project, Maternal and Child Health Bureau, HRSA grant 6t71MC00009. We would like to thank all of the schools and school personnel that participated in this study. 


\begin{abstract}
Objective: To explore barriers and facilitators to implementing and sustaining Healthy Choices, a three-year multi-component obesity prevention intervention implemented in middle schools in Massachusetts.
\end{abstract}

Methods: Using purposive sampling, 56 in-depth interviews were conducted with middleschool employees representing different positions (administrators, teachers, food service personnel, and employees serving as intervention coordinators). Interviews were recorded and transcribed. Emergent themes were identified using thematic analyses.

Results: State-mandated testing, budget limitations, and time constraints were viewed as implementation barriers while staff buy-in and technical assistance were seen as facilitating implementation. Respondents felt that intervention sustainability was dependent on external funding and expert assistance.

Conclusions and Implications: Results confirm the importance of gaining faculty and staff support. Schools implementing large scale interventions should consider developing sustainable partnerships with organizations that can provide resources and ongoing training. Sustainability of complex interventions may depend on state-level strategies that provide resources for implementation and technical assistance.

Word count: 150 
The scope and consequences of pediatric obesity in the United States are well

5 documented. ${ }^{1,2}$ Schools are a strategic organizational setting for obesity prevention, but school-

6 based interventions addressing lifestyle behaviors to prevent obesity have had mixed success, 3,4

7 which has led to calls for comprehensive approaches to obesity prevention that address multiple

8 levels in schools or in after-school settings. ${ }^{4,5}$ Multi-component approaches for obesity

9 prevention may place unknown demands on organizational systems, including schools,

10 particularly when evidence-based interventions are implemented on a wide scale. There is,

11 however, limited available information about how contextual factors influence implementation

12 and sustainability of school-based multi-component interventions. Previous research has

13 determined that employing district level coordinators, having administrative support, having an

14 effective program champion, and employing a team approach are important for intervention

15 implementation, ${ }^{6-11}$ yet only limited evaluations examining the implementation processes have

16 been conducted. ${ }^{4}$ Qualitative research methods are ideally suited to explore the process of

17 implementing school-based health promotion programs, and the objective of this case study was

18 to use qualitative research methods to explore barriers and facilitators to implementing and

19 sustaining a multi-component intervention school-based intervention. 


\section{Healthy Choices}

Healthy Choices was a multi-component intervention designed to increase physical

5 activity and healthy eating and to decrease TV viewing, with the goal of reducing overweight

6 and obesity. ${ }^{12}$ Healthy Choices brought together 2 previously evaluated programs: Planet Health

7 and Healthy Choices-After School. Planet Health, an interdisciplinary curriculum, has been

8 shown to improve health behaviors and reduce obesity in middle school girls. ${ }^{13}$ Healthy

9 Choices-After School was an after-school program that offered opportunities for physical

10 activity and/or nutrition education. The Healthy Choices intervention also included use of an

11 assessment tool (the School Health Index) to help schools identify the strengths and weaknesses

12 of health-related programs, and create an action plan. ${ }^{14}$

13 Healthy Choices was a collaboration between the Massachusetts Department of Public

14 Health (MDPH) and Blue Cross Blue Shield of Massachusetts (BCBS-MA). All schools that

15 applied for funding received funding: $\$ 5,000$ in year $1, \$ 3,000$ in year 2 , and $\$ 1,000$ in year 3 .

16 Funds were used to provide staff stipends, purchase supplies, and supplement intervention-

17 related activities. MDPH employed 4 regional coordinators who provided support to

18 participating schools to aide intervention implementation. Additionally, MDPH and BCBS-MA

19 provided training on Planet Health and sponsored an annual meeting. Healthy Choices began in

20 the 2004-2005 school year with 69 schools. Healthy Choices II, began in 2005-2006 when an

21 additional 51 schools received their first year of funding (total of 120 schools). 
A staff member at each funded school volunteered to be the Healthy Choices school

2 coordinator and created a team to assist in intervention implementation. Most teams included

3 classroom teachers, PE teachers, and the school nurse. A few also included administrators, food

4 service personnel, and students. Participating schools were encouraged to meet intervention

5 benchmarks: 1 ) have $1+$ teacher in each core subject area (language arts, math, science, social

6 studies) teach 2-3 Planet Health lessons each year, 2) implement 1+ before- or after-school

7 program focused on nutrition or physical activity each year, 3) implement 1+ yearly campaign

8 promoting the 5-2-1 message (eat $\underline{5}$ or more fruits and vegetables, watch less than $\underline{2}$ hours of

9 screen time and get at least $\underline{1}$ hour of physical activity daily), 4) complete Module 1 of the

10 School Health Index (School Health and Safety Policies and Environment), and 5) initiate 1+

11 policy or environmental change to support healthy eating and/or active living in years 2 and 3.

12 School coordinators documented all activities in annual progress reports.

\section{Participants and Recruitment}

This present study is limited to Healthy Choices-II schools. Using process data collected

18 through the end of year 2, each school's intervention activities were determined (i.e., number of

19 Planet Health lessons taught, number of teachers who received Planet Health training, number of

20 before/ after-school programs implemented, number of 5-2-1 campaigns implemented, number

21 of policy and environmental changes) and reach (i.e., percent of students involved). This

22 information was used to create an implementation score. Schools with the highest and lowest

23 score in each of the 4 areas of the state were identified (total number of schools $=8$ ). Regional 
1 coordinators contacted school coordinators at identified schools and described the voluntary

2 study. One school did not respond to the regional coordinator's requests so another school was

3 selected as a replacement. Interview guides for each position to be interviewed (administrator,

4 food service personnel, physical education (PE) teacher, school coordinator, classroom teacher

5 using Planet Health, and classroom teacher not using Planet Health) were developed using an

6 ecological framework. ${ }^{1.5}$ The interview guides included questions that were asked of all

7 interviewees (5 questions) as well as position specific question (2-5 questions) and were pilot-

8 tested in 2 schools to assess flow.

9 After agreeing to participate in the study, school coordinators identified potential

10 interviewees who were involved in Healthy Choices (e.g. members of the Healthy Choices team)

11 or teachers within their cluster to participate. The food service personnel asked to participate

12 were those in charge of food services at the participating schools. Most schools only had one PE

13 teacher, but if a school had employed more than one, the school coordinator identified the PE

14 teacher who was most involved in the intervention. School coordinators forwarded their list of

15 potential interviewees to study staff who scheduled interviews. If needed, the regional

16 coordinators and school coordinators assisted with scheduling. As the guides were not modified

17 after pilot-testing, the 2 schools participating in the pilot-test were included in the analysis (total

18 number of school $=10$ ). This study was approved by the Institutional Review Board at Harvard

19 School of Public Health and all interviewees provided written informed consent.

\section{Analysis}


Trained interviewers conducted all interviews, and interviews were audio-recorded and

2 transcribed without names of interviewees ${ }^{16}$ (position within the school remained in the

3 transcript) or the school's level of intervention implementation. Interviews lasted between 20-60

4 minutes. Analysis was a multistep process. Several transcripts were read by a graduate level

5 researcher trained in qualitative research methods to create an initial codebook who then coded

6 all transcripts with new codes being created when needed. Another researcher trained in

7 qualitative research methods reviewed coding, and differences were discussed. The two

8 researchers worked collaboratively to collapse codes using the thematic analysis technique to

9 identify key concepts and themes by staff position. ${ }^{17,18}$ Level of intervention implementation

10 was then assigned to each transcript, and themes were examined across staff positions and level

11 of intervention implementation.

\section{RESULTS}

Interviews ( $\mathrm{n}=56)$ were conducted with school coordinators $(\mathrm{n}=11$, one school has 2

17 school coordinators), administrators ( $\mathrm{n}=12$, at 2 schools the principal asked that the assistant

18 principal be interviewed), PE teachers $(n=9)$, food service personnel $(n=7)$, classroom teachers

19 using Planet Health $(\mathrm{n}=9)$, and classroom teachers not using Planet Health $(\mathrm{n}=8)$. Three

20 individuals served 2 roles (e.g., school coordinator and PE teacher) and were interviewed for

21 both positions. None of the approached individuals actively declined to participate: however, 5

22 planned interviews (1 PE teacher, 3 food service personnel, and 1 teacher using Planet Health)

23 were not completed due to scheduling difficulties and/or missed appointments. There were no 
1 differences in identified themes by level of intervention implementation. The identified themes

2 are presented below (themes are italicized) and themes by position can be seen in Table 1 .

\section{Barriers to Implementation}

Themes that were identified when examining barriers to implementation focused on using

8 Planet Health and making changes in the dining services, as well as the overarching barrier of

9 limited time (see Table 2 for emergent themes with representative quotes). Themes related to

10 using Planet Health included unwillingness of some teachers to use the curriculum; difficulty in

11 training teachers; and time constraints due to state-mandated testing [Massachusetts

12 Comprehensive Assessment System (MCAS) exams], even though it was designed to be tied to 13 the state standards.

14 A theme within the interviews with food service personnel was that budget limitations 15 made it difficult to make changes in offered foods. Food service personnel reported that dining

16 services need to meet the "bottom line," and this required offering foods that students will buy,

17 and that healthful food options were less likely to be purchased then unhealthful options.

18 Additionally, a theme that emerged in interviews with administrators and school coordinators

19 was the perceived reluctance of food service personnel to make changes.

\section{Facilitators of Implementation}


The themes (see Table 3) that emerged when examining facilitators were not clearly tied

2 to specific intervention components, but rather focused on the implementation process. At the

3 interpersonal level, a theme that emerged with in the interviews with school coordinator and

4 administrators was the importance of the school coordinator's strong relationships with faculty

5 and staff was seen as contributing to the use of Planet Health, as they could discuss the

6 curriculum one-on-one to alleviate concerns related to its use, and to creating an active Healthy

7 Choices team Across the majority of positions interviewed, having a program champion and

8 employing a team approach were themes identified as facilitating intervention implementation.

9 Identified organizational level themes included having administrative and staff buy-in and the

10 external support offered (e.g., regional coordinators, Planet Health trainings).

\section{Achieving Sustainability}

15 A theme that emerged in the interview with school coordinators, teachers, and administrators

16 was that reducing MACS pressures would be essential for intervention sustainability, as this

17 would enable faculty, staff, and students to increase their involvement (see Table 4).

18 Additionally, interviewees felt that reduced MCAS pressures would contribute to increased use

19 of Planet Health. Interviewees did not identify ways to reduce MCAS pressures.

20 Sustainability was seen as hinging on maintaining existing supports while acquiring

21 additional ones, as evidenced in the following identified themes: the importance of continued

22 buy in from administration and staff and necessity of parental/community support were. Two

23 additional themes emerged when examining possible sustainability: Importance of future funding 
1 and maintaining contact with outside experts. Outside funding was viewed as being necessary to

2 continue implemented changes (e.g., new physical activity programs) while outside experts

3 (e.g., regional coordinators, other experts) who could provide information about resources,

4 funding opportunities, etc. were viewed as being essential for sustainability. It is worth noting

5 that several food service personnel felt that food services should be included in administrative

6 meetings where changes in food services are discussed.

\section{DISCUSSION}

12 Schools participating in this case study meet most of the intervention implementation

13 benchmarks, and interviewees did not view the intervention as being too complex or

14 burdensome. Many participants, with the exception of administrators and school coordinators,

15 focused on the intervention component germane to them, although most were aware that Healthy

16 Choices included multiple intervention components. This suggests that greater work should have

17 been undertaken to foster a clear understanding of all intervention components.

18 Identified facilitators to intervention implementation have been corroborated by others. ${ }^{6-}$

$19{ }^{11,19}$ Interestingly, interviewees noted the importance of the technical support offered by MDPH

20 and BCBS-MA more often than the financial support, which suggests the importance of

21 partnering with outside organizations for consultation. Although schools were encouraged to

22 create partnerships with outside organizations, MDPH and BCBS-MA were the only outside

23 partners that were mentioned as facilitating implementation which may be evidence of a lack of 
1 outside partnerships suggesting that additional training was needed on creating and sustaining

2 such relationships.

3 The primary identified barrier to implementing Planet Health was state-mandated testing,

4 despite the fact that the curriculum aligns with the Massachusetts Curriculum Framework. This

5 indicates the importance of reminding teachers of this, and it $\mathrm{t}$ may be beneficial for teachers

6 considering using Planet Health to talk with others who have successfully used it. The belief that

7 implementing large scale interventions and/or curriculums takes away time from preparing for

8 testing is important, and not specific to this case study. ${ }^{7,}{ }^{11}$ Strategies are needed that enable

9 schools to balance obesity prevention efforts with testing requirements. It may be unrealistic to

10 expect teachers to adopt and maintain the use of a curriculum such as Planet Health without

11 policy changes that support this adoption. Similarly, the adoption of policies limiting sales of

12 unhealthy foods removes the onus of responsibility from food service personnel to the school at

13 large. Clearly policy and environmental changes are needed to promote healthy school

14 environments, and Massachusetts passed legislation in 2010 that supports such guidelines

15 (M.G.L. c. 111, s. 223, 2010).

16 Although teachers volunteered to teach Planet Health, they were not necessarily involved

17 in the decision to apply for funding. Similarly, food service personnel may not have involved in

18 the decision to participate. Future multi-component interventions should not just rely on teachers

19 and food service personal to implement the intervention, but should provide them and other key

20 leaders the opportunity to be actively involved in intervention development. There is a need for

21 greater collaboration between administrators, teachers, food service personnel, as well as

22 parents. 
School coordinators felt garnering community/parental support would contribute to

2 sustainability. In the future, it would be important for funders to consider devoting more time

3 and energy to help schools identify ways to involve the community, partners, parents, and

4 outside experts. This is supported by findings from other large school-based interventions. For

5 example, the factors seen as being important for the institutionalization of the Child and

6 Adolescent Trial for Cardiovascular Health $(\mathrm{CATCH})$ intervention at 5-years post intervention

7 were having continued training, identifying program champions to assume training

8 responsibility, and having schools devote resources to continued training, in addition to having a

9 flexible intervention compatible with the school environment. ${ }^{20}$ Study results suggest that

10 modest investments in coordination and training by state public health agencies may help support

11 schools and staff in efforts to sustain multi-component interventions in their community context.

12 This case study has several limitations. It was designed as an in-depth exploration of the

13 process of implementing Health Choices; thus, results are not generalizable. Interviews were

14 conducted at 1 time point, during the third year of the intervention, rather than at several points

15 throughout the intervention period. Additionally, we used purposive sampling; individuals

16 identified by school coordinator as potential participants may have been more invested in the

17 intervention than though those that were not approached. We also unable to conduct all planned

18 interviews. It is possible that the individuals with whom we were unable to schedule interviews

19 viewed Healthy Choices differently than those who were interviewed. Furthermore, although all

20 schools who completed the brief proposal received funding, schools participating in Healthy

21 Choices may differ from schools that did not participate in Healthy Choices. 


\section{IMPLICATIONS FOR RESEARCH AND PRACTICE}

$4 \quad$ Results of this case study suggest that before implementing school-based multi-

5 component obesity prevention programs, it is important to gain the support of faculty and staff,

6 including food service personnel through relationship building by a program champion and

7 promoting awareness and understanding of all intervention components. This will likely enhance

8 implementation and sustainability by promoting buy-in. Findings also support continued

9 technical assistance from outside experts, as school administrators and staff predict difficulty in

10 sustaining Healthy Choices when operating in isolation. Results also support the need for

11 supportive changes in state-level school nutrition and PE/physical activity policies, and testing

12 mandates. Although participating schools were interested in promoting healthful behaviors

13 among their students, the emphasis remains on academic success measured by state-mandated

14 testing.

15

16 


\section{REFERENCES}

2

3

4 1. Koplan JP, IOM. Progress in preventing childhood obesity: How do we measure up? .

5 Washington, D.C.: The National Academies Press; 2007.

6 2. Ogden CL, Carroll MD, Curtin LR, Lamb MM, Flegal KM. Prevalence of high body

7 mass index in US children and adolescents, 2007-2008. JAMA. 2010;303:242-249.

8 3. Katz DL. School-based interventions for health promotion and weight control: not just

9 waiting on the world to change. Annu Rev Public Health. 2009;30:253-272.

10 4. Peterson KE, Fox MK. Addressing the epidemic of childhood obesity through school-

11 based interventions: what has been done and where do we go from here? J Law Med

12 Ethics. 2007;35:113-130.

13 5. Story M, Nanney MS, Schwartz MB. Schools and obesity prevention: creating school

14 environments and policies to promote healthy eating and physical activity. Milbank $Q$.

$15 \quad 2009 ; 87: 71-100$.

16 6. Bauer KW, Yang YW, Austin SB. "How can we stay healthy when you're throwing all of

17 this in front of us?" Findings from focus groups and interviews in middle schools on

18 environmental influences on nutrition and physical activity. Health Educ Behav.

$19 \quad 2004 ; 31: 34-46$.

20 7. Austin SB, Fung T, Cohen-Bearak A, Wardle K, Cheung LW. Facilitating change in

21 school health: a qualitative study of schools' experiences using the School Health Index.

22 Prev Chronic Dis. 2006;3:A35. 
1 8. Thaker S, Steckler A, Sanchez V, Khatapoush S, Rose J, Hallfors DD. Program

2 characteristics and organizational factors affecting the implementation of a school-based

3 indicated prevention program. Health Educ Res. Apr 2008;23:238-248.

49 Kam CM, Greenberg MT, Walls CT. Examining the role of implementation quality in 5 school-based prevention using the PATHS curriculum. Promoting Alternative THinking $6 \quad$ Skills Curriculum. Prev Sci. 2003;4:55-63.

7 10. Hall WJ, Zeveloff A, Steckler A, et al. Process evaluation results from the HEALTHY $8 \quad$ physical education intervention. Health Educ Res. 2012;27:307-318.

9 11. Levine E, Olander C, Lefebvre C, Cusick P, Biesiadecki L, McGoldrick D. The Team 10 Nutrition pilot study: lessons learned from implementing a comprehensive school-based 11 intervention. J Nutr Educ Behav. 2002;34:109-116.

12 12. Austin SB, Spadano-Gasbarro J, Greaney ML, et al. Disordered weight control behaviors 13 in early adolescent boys and girls of color: an under-recognized factor in the epidemic of $14 \quad$ childhood overweight. J Adolesc Health. 2011;48:109-112.

15 13. Gortmaker SL, Peterson K, Wiecha J, et al. Reducing obesity via a school-based 16 interdisciplinary intervention among youth: Planet Health. Arch Pediatr Adolesc Med. $17 \quad 1999 ; 153(4): 409-418$.

18 14. Centers for Disease Control and Prevention. School Health Index: A Self-Assessment and 19 Planning Guide. Atlanta, Georgia. 2012.

20 15. McLeroy KR, Bibeau D, Steckler A, Glanz K. An ecological perspective on health 21 promotion programs. Health Educ Q. 1998;15:351-377.

22 16. Maxwell JA. Qualitative Research Design: An Interactive Approach. Sage Publications 23 Applied Social Science Methods Series: Thousand Oaks, CA; 2005. 
1 17. Miles MB, Huberman AM. Qualitative Data Analysis. 2 ed. Newbury Park, CA: Sage; 21994.

3 18. Guest G, MacQueen KM, Namey EE. Applied Thematic Analysis. Washington, D.C.: $4 \quad$ Sage; 2012.

5 19. Jain A, Langwith C. Collaborative school-based obesity interventions: lessons learned 6 from 6 southern districts. J Sch Health. 2013;83:213-222.

7 20. Hoelscher DM, Feldman HA, Johnson CC, et al. School-based health education programs 8 can be maintained over time: results from the CATCH Institutionalization study. Prev $9 \quad$ Med. 2004;38:594-606. 
Table 1: Emergent Themes Related to Barriers and Facilitators of Implementing and Sustaining Healthy Choices by Position Interviewed ( $\mathrm{n}=56$ ).

Themes

\begin{tabular}{|c|c|c|c|c|c|}
\hline \multicolumn{6}{|c|}{$\underline{\text { Position }}$} \\
\hline$\underline{\text { Administrators }}$ & $\begin{array}{l}\underline{\text { Food }} \\
\text { service } \\
\text { personnel }\end{array}$ & $\begin{array}{l}\text { Physical } \\
\text { Education } \\
\text { teacher }\end{array}$ & $\begin{array}{l}\text { School } \\
\underline{\text { Coordinators }}\end{array}$ & $\begin{array}{l}\text { Teachers } \\
\underline{\text { using }} \\
\frac{\text { Planet }}{\text { Health }}\end{array}$ & $\begin{array}{l}\frac{\text { Teachers not }}{\text { using Planet }} \\
\text { Health }\end{array}$ \\
\hline
\end{tabular}

\section{Barriers to implementation of Healthy Choices}

Barriers related to Planet Health

- Time constraints due to state-mandated testing

- Unwillingness of some teachers to use Planet Health

- Training teachers in Planet Health

Barriers related to making changes in dining service

- Perceived reluctance of food service personnel to make changes

- Budget limitations make it difficult to make changes in the dining services

Overarching barrier

- General time constraints

\section{Facilitators of implementation of Healthy Choices}

Interpersonal-level facilitator

- Having a program champion and employing a team approach

- School coordinator's strong relationships with faculty and staff Organizational-level facilitators

- Administrative \& staff buy-in

- External support offered

\section{Sustainability of Healthy Choices}

- Reducing MCAS-related pressures

- Continued buy-in and support from the administration and staff

- Necessity of parental/community support

- Importance of future funding

- Maintaining contact with outside experts 
Table 2: Emergent Themes Related to Barriers Impeding the Implementation of Healthy Choices with Representative Quotes.

\section{Barriers related to Planet Health}

- Time constraints due to state-mandated testing

"I think Planet Health has been something that not every teacher is really excited to tackle, even if they get trained, because this district places such a high emphasis on academics that, even though the classes are directed towards content area." (School coordinator)

- Unwillingness of some teachers to use Planet Health

"They enjoyed the training, they really liked it, but, we have a lot of new teachers in that area, so they're so focused on their own curriculum that it was kind of hard to sell." (School coordinator)

- Training teachers in Planet Health

"It's not that the [Planet Health] curriculum isn't received well, or liked, when you get the bodies at the training, it's just getting them to the training."

\section{Barriers related to making changes in dining service}

- Perceived reluctance of food service personnel to make changes

"So they'll do it for a week [make changes to food being served]. Then I'll hear that they're not seeing it anymore, and I'll want to know why. So from the staff's point of view, "It doesn't sell. Why should I do it?" This is what I get from my staff, and I find that a total barrier. Other than having to just put my foot down and say, "What I say to do, you do." And I don't like to direct that way. I don't." (Food service personnel)

- Budget limitations make it difficult to make changes in the dining services

"I don't know about other school systems; I know about our school system, and we're self providing, meaning that we don't have tax dollars. So, we are like a business."

\section{Overarching barrier}

- General time constraints

"In trying to get some of my colleagues on-board, that's been the most difficult for me, and, like I said, primarily their reasons have been, 'I have too many other things to do, too many other pressures"” (School coordinator) 
Table 3: Emergent Themes Related to Facilitators of Implementation of Healthy Choices with Representative Quotes.

\section{$\underline{\text { Interpersonal-level facilitators }}$}

- Having a program champion and employing a team approach

"I would have to give a lot of the credit to [school coordinator] ..... she has really taken this whole project and devoted serious planning time, and had the committee of teachers that have stayed committed, people who have come on-board to run some of the after school things, but [school coordinator] has been the person who has stayed on target ... I think [the school coordinator's] implementation of it has been key in our success with it so far." (Administrator)

- Strong relationships to faculty and staff

"... getting that team on-board, and you really need the principal and the vice-principal, like, nurse, health teacher, PE teacher, life skills teacher. They all have to be a part of this, and they all have to be a strong team." (School coordinator)

\section{$\underline{\text { Organizational-level facilitators }}$}

- Administrative \& staff buy-in

"I think that the whole school is on-board with it. My principal is definitely on-board with it, and she is someone who loves her chocolate and loves snacks, and she has really, stood by us, and really reinforced the message that we're trying to get out. ...we have that support - the school nurse, the counselors, I think the teachers are on-board. And so, I think, the school as a whole buys into it." (School coordinator)

\section{- External support offered}

"We do get a lot of feedback and tips from the folks that gave us the money. I mean, Blue Cross \& Blue Shield, and the HC liaisons are extremely helpful. I mean, a week doesn't go by without an e-mail, and some of them I print and put in a folder, but find myself later on going and using, and sending out to other folks. " (School coordinator) 
Table 4: Emergent Themes Related to Sustainability of Healthy Choices with Representative Quotes.

- Reducing MCAS-related pressures

"To focus on wellness, you have to reduce the pressure of MCAS. The way we teach, the way we structure our day, the way we use free time for students It's all directed towards MCAS. And, until that pressure is relieved, I think . . . districts will do the best they can, but they will not be able to do what they should do or what they could do. . . You're swimming in an uphill stream." (School coordinator)

- Continued buy-in and support from the administration and staff

"You have to get people on-board, you have to have a good committee that's willing to do the work, and really get out there and spread the word. But you can't do it all yourself. I think that's the tough part. But, I think I'm fortunate that we do have a good committee. The School Nurse is an important piece of it. The Principal has to be on-board. And, if they're not, you're not going to get very far." (School coordinator)

\section{- Necessity of parental/community support}

"Some community support... some more grants to maybe, keep the thing going. And you know, you can do, find people that would be willing to donate their time, rather than pay to like run after school programs; and really hit the parents, and see who's got some talents out there." (School coordinator)

- Importance of future funding

"But that funding piece is extremely important, to keep the activities going. It's not as important in keeping, maybe, the teacher teaching the Healthy Choice piece; but, it is to get that whole activity level. And that activity level, and keeping those kids engaged... is what's making this work. But, that takes funding." (Food service personnel)

- Maintaining contact with outside experts

"Just keep up with the check-ins ... just someone there, kind of giving you reminders, or suggestions... 'Oh, did you hear about this school doing this,' kind of seeing what other schools are doing... tying people together..." (School coordinator) 